\title{
General transfer across sensory modalities survives reductions in the original conditioned reflex in the rabbit
}

\author{
E. JAMES KEHOE, LOUISE D. MORROW, and PHOEBE E. HOLT \\ University of New South Wales, Kensington, New South Wales, Australia
}

\begin{abstract}
Two experiments demonstrated that transfer of training between CSs from different sensory modalities survived substantial reductions in responding to the first CS. In both experiments, animals received three stages of training. Stage 1 entailed CS-US training with a CS from one modality (e.g., light), and Stage 3 entailed CS-US training with a CS from another modality (e.g., tone). The experiments differed in treatment during Stage 2. In Experiment 1, animals either remained in their home cages or received unreinforced exposures to the first CS, which extinguished the original CR. In Experiment 2, the animals received either continued CS-US training or exposure to the CS and US but at a long interval $(2,800 \mathrm{msec})$, which eliminated the original CR. As the baseline for detection of transfer effects, each experimental group had a control group that received Stage 1 training with a 2,800-msec CS-US interval, which produced minimal CR acquisition. The results of both experiments revealed substantial positive transfer across CS modalities regardless of the treatment during Stage 2. The transfer did not appear immediately on test presentations of the second CS in Stage 3. Rather, the transfer appeared as an enhancement in the rate of $\mathrm{CR}$ acquisition after reinforced training with the second CS had commenced. The results are discussed with respect to stimulus generalization, neutralization of background stimuli, and learning processes superordinate to specific associations.
\end{abstract}

Kehoe and Holt (1984) recently examined transfer of training in an AB-CB paradigm that used classical conditioning of the rabbit's nictitating membrane response (NMR). They first conducted AB training, in which $A$ was a conditioned stimulus (CS) in one sensory modality (e.g., light) and B was a shock unconditioned stimulus (US). After conditioned responses (CRs) were established to the initial CS, transfer testing was begun. The $C$ item was a new $C S$ in another sensory modality (e.g., tone). At the beginning of testing, the new CS was presented four times to determine whether there was any "immediate transfer" from the initial CS to the new CS, that is, cross-modal stimulus generalization. In fact, immediate transfer was negligible; the mean level of responding on the four test presentations was less than $10 \% \mathrm{CRs}$, which did not differ from control conditions. After assessing immediate transfer, Kehoe and Holt conducted CB training in order to reveal any "general transfer." General transfer was evidenced by extremely rapid CR acquisition to the new $C S$ in the AB-CB condition as compared with control conditions that received initial exposure to either (1) the experimental chambers or (2) the original CS and US but separated by a long CS-US interval.

This research was supported by the School of Psychology, University of New South Wales, and the Australian Research Grants Scheme (A27815154). Requests for reprints should be sent to E. James Kehoe, School of Psychology, University of New South Wales, P.O. Box 1, Kensington, New South Wales 2033, Australia.
Some instances of general transfer may rely on mechanisms that become independent of the earlier associations (Bunch, 1939). In human verbal learning, retention of specific associations declines rapidly, but the magnitude of general transfer is constant over retention intervals of weeks in duration (e.g., Bunch, 1936, 1944; Bunch \& McCraven, 1938; Ellis, 1965, pp. 39-41). Similar results have been obtained in animal learning. Bunch (1939) examined transfer from a right-turn habit to a left-turn habit in a T-maze. After retention intervals of $0-2$ days, the transfer was negative in direction, as would be expected for two physically antagonistic responses. However, longer retention intervals ranging up to 28 days yielded some positive transfer. Consequently, Bunch concluded that there were separate specific and nonspecific factors that could independently influence transfer even in opposite directions. Although the magnitude of general transfer does not appear to depend on the retrieval of the specifics of the original learning, general transfer effects may not survive deliberate attempts to disrupt the original learning. Recently, Westbrook and Homewood (1982, Experiment 6) showed that taste aversion learning with one flavor (e.g., salt) facilitated the rate of taste aversion learning with a new, orthogonal flavor (e.g., sucrose). If, however, the original aversion was extinguished prior to training with the second flavor, the facilitation failed to appear. Consequently, the present experiments were conducted to determine whether or 
not the general transfer across CS modalities observed by Kehoe and Holt would survive deliberate reductions in the strength of the original conditioned reflex.

\section{EXPERIMENT 1}

The present experiment was designed to examine cross-modal transfer after the original conditioned reflex had been extinguished (cf. Westbrook \& Homewood, 1982, Experiment 6). Four groups of animals were used. Two groups received initial training with a CS from one sensory modality at a 400 msec CS-US interval. Then one group of subjects remained in their home cages while the other group received CS-alone presentations intended to extinguish the CR. Both groups then received reinforced training with a new CS from another sensory modality. As baselines for the detection of transfer effects, two control groups received initial training with a long, 2,800-msec CS-US interval, which yields negligible $\mathrm{CR}$ acquisition. Following initial exposure to the widely separated CS and US, one control group remained in the home cages and the other group received CS-alone presentations. Then both control groups received reinforced training with the alternate CS. In all four groups, the CS-US interval in the final stage was $800 \mathrm{msec}$. This interval produces a moderate rate of CR acquisition that avoided either ceiling or floor effects in detecting transfer (Kehoe \& Holt, 1984; Smith, Coleman, \& Gormezano, 1969).

The baseline condition was designed to fulfill two criteria: (1) the same exposure to the apparatus, CS, and US as received by the experimental groups, and (2) minimal excitatory or inhibitory conditioning during initial training. The $2,800-\mathrm{msec}$ CS-US interval was chosen as the baseline condition because it clearly meets the first criterion and produces a very low level of excitatory conditioning in the rabbit NMR preparation (Kehoe, Gibbs, Garcia, \& Gormezano, 1979; Kehoe \& Holt, 1984). Empirically, Kehoe and Holt (1984, Experiment 2) have compared transfer after initial training with a 2,800 -msec CS-US interval versus a rest control that received only exposure to the experimental chambers. In subsequent training with a new CS in another modality, the animals with prior training under the 2,800 -msec CS-US interval showed slightly faster CR acquisition than the rest of the control animals, but the differences were not significant. Thus, the 2,800 -msec interval baseline certainly does not exaggerate transfer by retarding subsequent acquisition to the new CS. If anything, initial training with a 2,800-msec interval itself yields some facilitation and hence provides a conservative control for excitatory general transfer.

\section{Method}

Subjects. The subjects were 24 naive female albino rabbits (Oryctolagus cuniculus). On arrival, each rabbit was 70-80 days old and weighed approximately $1.5 \mathrm{~kg}$. All rabbits had free access to food and water in their home cages. The rabbits were exposed to the natural light/dark cycle which provided approximately $11 \mathrm{~h}$ of daylight during the period in which the present experiments were run (late June through August).

Apparatus. The apparatus and recording procedure for the nictitating membrane response were patterned after those of Gormezano (1966) and are detailed by Kehoe, Feyer, and Moses (1981). In brief, the subjects were trained individually in eight sound-attenuating, ventilated conditioning chambers. In each chamber, a rabbit was restrained in a Perspex box held in place between metal stays screwed to the floor. A speaker was mounted at a 45-deg angle $8 \mathrm{~cm}$ anterior to and $16 \mathrm{~cm}$ above the subject's head. The speaker provided an auditory CS, which was a $1,000-\mathrm{Hz}$, 88-dB (SPL) tone superimposed on an ambient noise level of $82 \mathrm{~dB}$ provided by an exhaust fan. An 8-W frosted neon light tube was mounted $4 \mathrm{~cm}$ above the speaker. The light tube served as a houselight and was flashed at a rate of $20 \mathrm{~Hz}$ in order to provide a visual CS. The duration of both CSs was $\mathbf{4 0 0} \mathrm{msec}$ regardless of the CSUS interval. The US was a 50-msec, 3-mA, 50-Hz ac shock delivered via stainless steel Autoclip wound clips positioned $10 \mathrm{~mm}$ apart and $15 \mathrm{~mm}$ posterior to the dorsal canthus of the right eye. The sequence and timing of stimulus events were controlled by an Apple II computer equipped with interfaces and software developed by Scandrett and Gormezano (1980).

Each rabbit's right external eyelids were held open by a No. 3 tailor hood mounted on a Velcro strap looped around the head. A muzzle-like headset, fitted about the snout, supported a transducer for monitoring movements of the nictitating membrane. A small hook was attached to a silk loop sutured in the nictitating membrane of the rabbit's right eye. The hook was connected by a thread to one end of an L-shaped piano wire lever, which mechanically transmitted the movement of the nictitating membrane to the transducer. Inside the transducer, movement of the lever rotated a disk of polarized filter that was interposed between a light-emitting diode and a phototransistor covered by a fixed polarized filter. Thus, rotation of the disk produced changes in the intensity of the light reaching the transistor through the fixed filter. The signal from the transistor was amplified and transmitted to an analog/digital converter attached to the computer.

Procedure. All rabbits received 1 day of preparation, 1 day of adaptation, 4 days in Stage 1,8 days in Stage 2 , and 6 days in Stage 3. On the preparation day, hair surrounding the rabbit's right eye was removed, and a small loop of silk ( 000 Dynex) was sutured into the nictitating membrane. On the adaptation day, the animal was placed in the conditioning apparatus for $70 \mathrm{~min}$, but neither a CS nor a US was presented.

Following adaptation, the animals were assigned to one of four groups. In Stage 1, Groups 4-E $(n=8)$ and 4-H $(n=8)$ received training at a CS-US interval of $400 \mathrm{msec}$ and Groups 28-E $(n=4)$ and $28-H(n=4)$ received a CS-US interval of $2,800 \mathrm{msec}$. Half of the animals in each group received the tone as the CS in Stage 1, and the other half of each group received the flashing light as the CS. Each training session consisted of $70 \mathrm{CS}$-US presentations and 3 nonreinforced CS presentations on Trials 20,40 , and 60 . The mean intertrial interval (ITI) was $60 \mathrm{sec}$ (range 40-80 sec).

In Stage 2, Groups 4-H and 28-H remained in their home cages. Groups 4-E and 28-E were given eight sessions of extinction training with the CS used in Stage 1. The initial four sessions of Stage 2 each contained 73 nonreinforced CS presentations (mean ITI = $60 \mathrm{sec}$, and the last four sessions each contained 110 nonreinforced CS presentations (mean ITI $=40 \mathrm{sec}$ ).

Stage 3 tested for cross-modal transfer. All subjects were presented with the CS not used in Stage 1. Each training session consisted of 73 trials (mean ITI $=60 \mathrm{sec}$ ). On the 1st day of Stage 3, Trials 1-4 were nonreinforced presentations of the new CS, which tested for immediate transfer. As in Stages 1 and 2, Trials 20, 40, and 60 were nonreinforced CS presentations. All other trials were CS-US trials. The CS-US interval was $800 \mathrm{msec}$ for all four groups.

A conditioned response (CR) was defined as any extension of the nictitating membrane exceeding $.5 \mathrm{~mm}$ and occurring after 
the onset of the CS but prior to the onset of the US. The data are reported as percentage CR. Responding was also examined in terms of certain criteria - for example, trial of the 10th CRbut these additional measures yielded the same pattern of results as the percentage CR measure. Preliminary examination of the response measurements revealed that the data from CS-US trials were virtually identical to data from CS-alone test trials. Unless otherwise noted, we will report data from CS-US trials. The data were analyzed using a set of planned orthogonal contrasts, and the rejection level was set according to a Type I decision-wise error rate of .05 .

\section{Results}

Figure 1a shows the mean percentage of CRs in Stage 1 for each group, plotted as a function of days of training. The 400-msec CS-US interval clearly produced faster and higher levels of CR acquisition than did the 2,800-msec CS-US interval. Responding in Groups 4-E and 4-H attained terminal levels exceeding $90 \%$ CRs, whereas responding in Groups 28-E and $28-\mathrm{H}$ never rose above $6 \% \mathrm{CRs}$. Statistical analysis confirmed that there was a significant main effect of CS-US interval $[F(1,20)=322.33]$, which interacted with the linear trend over days $[F(1,20)=164.44]$. Any other apparent differences between groups failed to attain statistical significance. In particular, the tone and light $C S$ appeared to be equal in salience. Across Groups 4-E and 4-H, the tone CS produced an overall mean of $78 \% \mathrm{CRs}$, and the light CS produced $75 \%$ CRs.

Figure $1 \mathrm{~b}$ shows the mean percentage of CRs during extinction training for Groups 4-E and 28-E. The performance functions indicate that the subjects in Group 4-E showed gradual extinction of their CRs, while Group 28-E continued to show virtually no responding. Analysis of the data from Group 4-E suggested that those subjects trained with tone in Stage 1 were more resistant to extinction than those subjects trained with light. On the last day of extinction, the

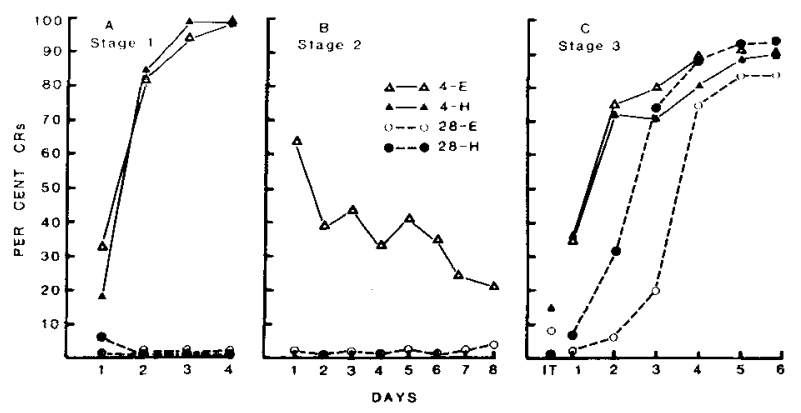

Figure 1. Mean percentage of CRs in Experiment 1 plotted as a function of days of training. Panel A shows the results of CS-US training in Stage 1; Groups 4-E and 4-H were trained with a $400-$ msec CS-US interval, and Groups 28-E and 28-H were trained with a 2,800-msec CS-US interval. Panel $B$ shows the results of extinction training for Groups 4-E and 28-E in Stage 2; Groups 4-H and 28-H remained in their home cages. Panel $\mathrm{C}$ shows the results of CS-US training with an alternate CS at an 800 -msec CS-US interval in Stage 3 . four subjects trained with tone showed response levels of $77 \%, 47 \%, 6 \%$, and $4 \%$ CRs, respectively, and the four subjects trained with the light showed response levels of $16 \%, 12 \%, 3 \%$, and $2 \%$ CRs, respectively. However, statistical analysis failed to reveal a significant difference between the two CS modalities $[F(1,8)=2.61, p>.05]$.

In Figure 1c, the left-hand set of points designated as "IT" shows the level of immediate transfer as assessed by the likelihood of responding on the first four presentations of the new CS in Stage 3. There was no consistent immediate transfer from Stage 1 to Stage 3. Specifically, Groups 4-E, 4-H, 28-E, and 28 -H showed mean levels of only $0 \%, 15 \%, 6 \%$, and $0 \%$ CRs, respectively. The only exception was one subject in Group 4-H, which showed CRs on all four presentations of the new CS. No other subject showed more than a single response.

Figure 1c also shows the mean percentage of CRs in Stage 3 across days of training. The data plotted for Group 4-E are based on six subjects. The data of two subjects in Group 4-E were excluded because they showed high levels of responding (viz, $77 \%$ and $47 \% \mathrm{CRs}$ ) at the end of the extinction procedure in Stage 2. The data plotted for Group 4-H are also based on six subjects. One subject died during Stage 2, and the one subject that showed complete immediate transfer was excluded so that its responding would not inflate the assessment of general transfer during reinforced training in Stage 3. However, when all live subjects were included, the $C R$ acquisition curves for Groups 4-E and 4- $\mathrm{H}$ differed little from those shown in Figure 1c. Specifically, across Days 1, 2, and 3 of Stage 3, all subjects in Group 4-E $(n=8)$ showed mean levels of $26 \%, 72 \%$, and $83 \%$ CRs, respectively, and all live subjects in Group 4-H $(n=7)$ showed mean levels of $46 \%, 76 \%$, and $74 \%$ CRs, respectively. Likewise, statistical analysis of the data from all the subjects yielded results identical to those of subjects that displayed relatively complete extinction of the original CR.

Inspection of Figure 1c reveals clear evidence of general transfer across sensory modalities. Groups 4-E and 4-H both showed more rapid $\mathrm{CR}$ acquisition to the new CS than did Groups 28-E and 28-H. The statistical analysis confirmed that the overall level of responding in Stage 3 was facilitated by Stage 1 training with another CS at the 400-msec CS-US interval relative to the 2,800 -msec CS-US interval $[F(1,12)=12.39]$. The effect of initial CS-US interval also interacted with the linear trend over days in Stage $3[F(1,12)=29.06]$. Further inspection of Figure 1c reveals that the level of transfer for Groups 4-E and 4-H was similar to that for their respective baseline groups, 28-E and 28-H. Although Group 28-E showed somewhat slower $C R$ acquisition than Group 28-H in Stage 3, statistical analysis failed to reveal 
a significant main effect $[F(1,12)=3.22, p>.05]$ or interaction involving the extinction versus home cage treatments.

The counterbalancing of light and tone across stages of training produced a significant interaction in Stage 3. Specifically, there was a significant interaction of modality counterbalancing $\times$ initial CS-US interval $\times$ linear trend over days $[F(1,12)=$ 5.09]. That is, in Groups 4-E and 4-H, the light-tone order tended to produce faster $C R$ acquisition in Stage 3 than did the tone-light order. In Groups 28-E and $28-\mathrm{H}$, the order of modalities did not seem to affect the rate of CR acquisition in Stage 3. Taking the data from Stages 2 and 3 together, there would appear to be some indication that the tone was slightly more salient than the light used in the present experiment. However, in Stage 1, saliency differences were not apparent. Furthermore, previous research with the same stimuli in the same apparatus did not reveal any differences in salience between the tone and the light in either initial training or transfer trainirg. (Kehoe \& Holt, 1984).

\section{Discussion}

The results of the present experiment indicate that general transfer across sensory modalities occurs despite demonstrable reductions in the overt strength of the original conditioned reflex. The present results are generally consistent with previous findings that general transfer occurs even when the specifics of the original association can no longer be retrieved (e.g., Bunch, 1939; Ellis, 1965). Conversely, the present results disagree with Westbrook and Homewood's (1982) finding that general transfer in aversion learning between distinctive flavors was eliminated by extinction of the original aversion.

A basic theoretical question concerns whether general transfer represents a form of stimulus generalization or an enhancement in the formation of a new, independent association. A stimulus generalization hypothesis would contend that the observed transfer reflects the ability of the association formed in initial training to withstand alterations in the CS, including a change in modality. Although there have been demonstrations that generalization across sensory modalities can occur on the basis of temporal patterns shared by otherwise distinct CSs (Friedes, 1974; Meck \& Church, 1982; Seraganian \& Popova, 1976), no such transfer appeared in the present results. On the operational side, the CSs were as distinct as possible: the visual CS was a flashing of the houselight, and the auditory CS was a continuous tone. On the outcome side, a generalization hypothesis would expect some immediate transfer during the first presentations of a new CS, particularly in Group 4-H, which was not exposed to the extinction procedure. Although one animal in Group 4-H did show $100 \%$ CRs on the first exposures to the second CS, this animal's datum supplies rather slim evidence for a stimulus generalization hypothesis. The aggregate of data collected in our laboratory has revealed no statistical evidence for immediate transfer across CS modalities in the rabbit NMR preparation. In the transfer experiments conducted so far, immediate transfer has been assessed by four presentations of the new CS prior to CS-US training in the final stage. Thus, any individual animal could show $0,1,2,3$, or 4 responses on the initial CS-alone trials. Including subjects from the present experiments and those used by Kehoe and Holt (1984), and from work in progress, 106 experimental subjects have received prior training with one $\mathrm{CS}$ at a relatively short CS-US interval and 98 control subjects have received either no prior training or prior exposure to a long CS-US interval. Among the experimental subjects, $77 \%, 15 \%, 4 \%, 1 \%$, and $3 \%$ showed $0,1,2,3$, and 4 responses, respectively. Similarly, among the control subjects, $83 \%, 11 \%, 5 \%$, $0 \%$, and $1 \%$ showed $0,1,2,3$, and 4 responses, respectively. Any apparent difference between the two distributions failed to attain statistical significance $\left[x^{2}(4)=2.80, p>.50\right]$.

Although it is possible to discount stimulus generalization as a source of general transfer in the present results, it is less easy to identify positively what is acquired during initial training that subserves general transfer. There are two major schools of thought on the issue. Some accounts contend that the establishment of the initial association also entails increases in the animal's overall learning ability and/or changes in some superordinate "tendency or strategy" that directly facilitates acquisition of subsequent associations (Restle, 1975, p. 154; cf. Bunch \& McCraven, 1938; Ellis, 1965, p. 302; Postman \& Schwartz, 1964; Thomas, 1970). Alternative accounts contend that general transfer arises indirectly from the neutralization of competing responses (Harlow, 1959) or competing stimulus dimensions (Mackintosh, 1977). In the case of the present experiment, training with the first CS would presumably reduce the effective salience of concomitant background stimuli and thereby reduce their ability to compete with the new CS for the attentional or associative resources of the animal (Seraganian, 1979; Westbrook \& Homewood, 1982). According to such a hypothesis, general transfer could be eliminated only if either the salience or associative strength of the background stimuli were increased prior to transfer training. The CS-alone extinction procedure used in the present experiment would seem unlikely to have done either.

\section{EXPERIMENT 2}

The present experiment examined cross-modal transfer after the strength of the initial conditioned reflex was reduced by increasing the CS-US interval (cf. Leonard, 1975; Prokasy \& Papsdorf, 1965). Pre- 
senting the US well separated from the CS but still in conjunction with the background stimuli would presumably allow them to regain their salience and acquire some associative strength (cf. Hinson, 1982).

\section{Method}

Subjects. The subjects were 24 naive female albino rabbits of the same age and weight as those used in Experiment 1.

Apparatus and Procedure. The apparatus and recording procedure were identical to those used in Experiment 1. All rabbits received 1 day of preparation, 1 day of adaptation, 4 days in Stage 1, 4 days in Stage 2, and 6 days in Stage 3. The flashing light was used as the CS in both Stage 1 and Stage 2, and the tone was used as the CS in Stage 3. The animals were assigned to one of three groups $(n=8)$. Each group was designated by the significant digits of the CS-US intervals in Stages 1 and 2, respectively. Specifically, Group 4-28 received a 400 -msec CS-US interval in Stage 1 and a 2,800-msec CS-US interval in Stage 2, Group 4-4 received a 400-msec CS-US in Stages 1 and 2, and Group 28-28 received a 2,800-msec CS-IJS interval in Stages 1 and 2. All groups received training with the tone CS at an 800 -msec CS-US interval in Stage 3. Each training session consisted of $70 \mathrm{CS}-U S$ presentations and 3 nonreinforced CS presentations on Trials 20,40 , and 60. However, on the 1st day of Stage 3, Trials 1-4 were nonreinforced presentations of the tone CS, which tested for immediate transfer. The mean ITI was $60 \mathrm{sec}$.

\section{Results}

Figure 2a shows the mean percentage of CRs in Stage 1 for each group plotted across 4 days of training. As was seen in Experiment 1, the 400 -msec CSUS interval produced rapid $C R$ acquisition to terminal levels exceeding $90 \%$ CRs, whereas the 2,800 msec CS-US interval produced response levels around 3\% CRs. Statistical analysis confirmed that there was a significant main effect of CS-US interval $[F(1,21)$ $=114.25]$, which interacted with the linear trend over days $[F(1,21)=132.16]$. Any other apparent differ-
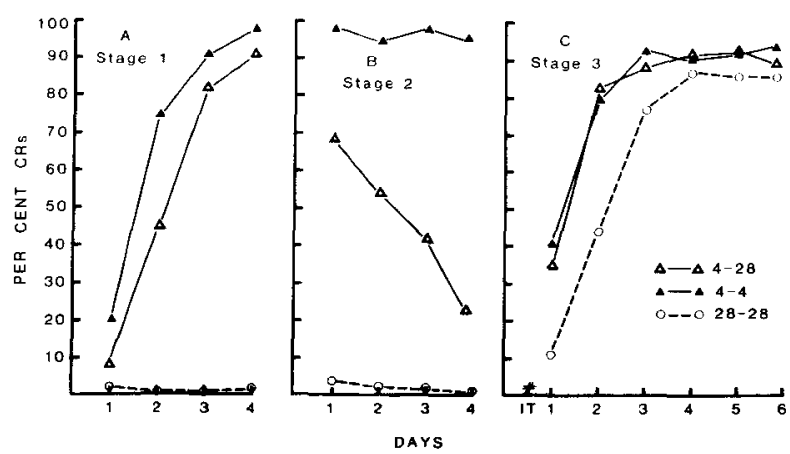

Figure 2. Mean percentage of CRs in Experiment 2 plotted as a function of days of training. Panel A shows the results of CSUS training with a light CS in Stage 1; Groups $4-4$ and $4-28$ were trained with a 400-msec CS-US interval, and Group 28-28 was trained with a 2,800-msec CS-US interval. Panel B shows the results of further CS-US training with the light CS in Stage 2; Group 44 continued with a 4BA-msec CS-US interval, Group 4-28 switched to a 2,800-msec CS-US interval, and Group 28-28 continued with a 2,800-msec interval. Panel $\mathbf{C}$ shows the results of CS-US training with a tone CS at an $800-\mathrm{msec}$ CS-US interval in Stage 3. ences between groups failed to reach statistical significance.

Figure 2b shows the mean percentage of CRs in Stage 2 for Groups 4-28, 4-4, and 28-28. Group 4-28, whose CS-US interval was increased from 400 to $2,800 \mathrm{msec}$, showed a steady decline in responding. One subject, however, maintained a level of $90 \%$ CRs throughout Stage 2. Because this animal failed to show any decline in its original $C R$, its data were omitted from further analysis. The remainder of the subjects in Group 4-28 showed 19\% CRs or less by Day 4 of Stage 2 . Group 4-4, which was maintained on a 400-msec CS-US interval during Stage 2, continued to show $90 \%-100 \%$ CRs. The lowest level of responding shown by any subject on a single day was $86 \%$ CRs. Group 28-28, which was maintained on a 2,800 msec CS-US interval, continued to show around $3 \%$ CRs. The highest level of responding shown by a single subject on a single day was $14 \% \mathrm{CRs}$.

In Figure 2c, the left-hand point indicated by the \# sign and designated as "IT" shows the level of responding on the first four presentations of the CS in Stage 3. There was no apparent immediate transfer from prior training with the light to the tone used in Stage 3. No animal in any group showed so much as a single $\mathbf{C R}$.

Figure 2c also shows the mean percentage of CRs in Stage 3 across days of training. Figure $2 \mathrm{c}$ reveals clear evidence of general transfer across sensory modalities. Groups 4-4 and 4-28 both showed more rapid CR acquisition than did Group 28-28. The statistical analysis confirmed that the level of responding in Stage 3 was facilitated by Stage 1 training with another CS at the 400-msec CS-US interval relative to the 2,800 -msec CS-US interval $[F(1,20)=4.41]$. Similarly, the effect of the Stage 1 CS-US interval also interacted with the linear trend over days in Stage $3[F(1,20)=5.05]$. In Group 4-28, the reduction in the initial CR produced by increasing the CS-US interval did not yield any discernible effect on the magnitude of cross-modal transfer, since Groups 4-4 and 4-28 had virtually identical $C R$ acquisition curves in Stage $3[F(1,20)<1]$.

\section{Discussion}

The present results confirm those of Experiment 1, namely, that general transfer across modalities occurs even after substantial reductions in the original conditioned reflex. Moreover, the present results are inconsistent with a background neutralization hypothesis. The continued presentation of the US during Stage 2 should have led to some increase in the salience and/or associative strength of background stimuli which would have provided competition with the new, discrete CS for the animal's processing resources. However, there was no discernible reduction in the magnitude of transfer. An advocate of a background neutralization hypothesis could argue that 
the number and spacing of the US presentations were insufficient to yield significant increases in the salience or associative strength of the background stimuli. However, there is converging evidence that similar parameters of US presentation can increase the salience or associative strength of the background cues. Empirically, prior exposure to the US alone subsequently retards $C R$ acquisition to a discrete $C S$ in the rabbit NMR preparation (Mis \& Moore, 1973). One account of the US preexposure effect is that the conjunction of the US with the background stimuli leads to their acquiring associative strength, which then partially blocks access of the added discrete CS to the animal's processing resources (e.g., Hinson, 1982). In Stage 2 of the present experiment, there were 280 US presentations delivered approximately once per minute at the rate of 70/day. Similarly, Mis and Moore (1973, Experiment 1) produced retardation of CR acquisition following 200 to 350 US presentations delivered every $30 \mathrm{sec}$ at the rate of 100 per day. Their US was virtually identical to the one used in the present experiment, that is, $50-\mathrm{msec} 3-\mathrm{mA}$ ac shock to the paraorbital region.

\section{GENERAL DISCUSSION}

The results of Experiments 1 and 2 provide substantial evidence that general transfer across modalities survives demonstrable reductions in the strength of the initial conditioned reflex. Two interpretative questions immediately arise: (1) Is the independence of general transfer and the original association more apparent than real? (2) What is acquired during the original training that subserves general transfer?

With regard to the question of independence between the original association and general transfer, it is clear that the overt conditioned reflex was eliminated by the extinction procedure in Experiment 1 and the increase in CS-US interval in Experiment 2. Thus, on a sheer performance basis, it is safe to conclude that the manifest strength of the original $C R$ cannot be used to predict the magnitude of general transfer. What remains unclear is whether the elimination of the overt CR reflects the destruction of an underlying association. Some theories of conditioning contend that the ordinary extinction procedure produces a decline in excitatory associative strength (e.g., Estes, 1955; Frey \& Sears, 1978; Mackintosh, 1975; Rescorla \& Heth, 1975; Rescorla \& Wagner, 1972; Sutton \& Barto, 1981). Alternative theories contend that the underlying association remains intact but its overt expression is reduced by the removal of contextual cues provided by the US (Frey \& Butler, 1977; Leonard, 1975), the acquisition of a separate inhibitory potential (Hull, 1943; Pavlov, 1927), or a deterioration in the strength of the US representation (Rescorla \& Heth, 1975; but see
Richards \& Sargent, 1983). Paradoxically, the answer to whether extinction represents the destruction of an underlying association rests on whether or not general transfer arises from nonspecific effects of acquisition training that are retained even if the original association is destroyed. The paradox can be seen most clearly when it comes to explaining the observation that successive acquisitions and extinctions become progressively faster (Frey \& Ross, 1968; Hoehler, Kirschenbaum, \& Leonard, 1973; Pavlov, 1927, p. 59; Smith \& Gormezano, 1965). This observation can be used to support the hypothesis that the original association remains intact after extinction. However, if there is an independent, nonspecific learning process, then it is equally plausible to argue that (1) acquisition training produces a new association, which each subsequent extinction destroys, and (2) the increase in the speed of acquisition and extinction results from a progressive increase in the efficiency of the nonspecific learning process (cf. Bunch, 1944).

Even if it could be established that extinction procedures ultimately destroy an association, identifying the point at which an association has in fact been destroyed would still pose a problem in transfer studies. Virtually every theory of conditioning assumes that the strength of an association can fall below a threshold for overt responding (e.g., Frey \& Sears, 1978; Hull, 1943; Reberg, 1972). Accordingly, even the reduction of overt responding to a minimal level may still leave some residual associative strength, which may be all that is necessary to produce transfer across modalities. A partial dependence between the strength of the original association and general transfer may also explain the apparent discrepancy between the present findings and those of Westbrook and Homewood (1982, Experiment 6). Westbrook and Homewood gave their animals one initial CS-US trial (e.g., saline-LiCl) and three CS-alone extinction trials (saline) prior to transfer training with the second CS (sucrose- $\mathrm{LiCl}$ ). Since taste aversion procedures yield both substantial acquisition and extinction within a minimal number of trials, Westbrook and Homewood's procedure may have more thoroughly extinguished the subthreshold associative strength than did the present preparation, which requires a much greater number of trials to produce overt changes in behavior. In the present experiment, there was a suggestion in the performance of Groups 28-E and 28- $\mathrm{H}$ in Experiment 1 that CS-alone presentations following initial exposure to a long CS-US interval produced some reduction in the rate of CR acquisition to the new CS. If the long CS-US interval produced some subthreshold associative strength, then the present extinction procedure may have been sufficient to destroy the original association and eliminate general transfer. Accordingly, brief initial acquisition training that produces a weak overt $C R$, and presumably a weak association, might also pro- 
duce a general transfer effect that disappears after extinction of the original CR.

Regardless of whether or not general transfer is entirely independent of the original association, the mechanism that subserves general transfer remains mysterious. Two candidates would appear to be unlikely: (1) General transfer might simply result from adaptation to the apparatus or development of a "US representation"' (Rescorla \& Heth, 1975). However, several demonstrations of general transfer with the NMR and other preparations have included a control condition with the same exposure to the apparatus, initial CS, and US as the transfer condition (Kehoe \& Holt, 1984; Thomas, Miller, \& Svinicki, 1971; Westbrook \& Homewood, 1982). In the present experiments, the only difference between the "control" and "experimental" conditions was in fact the CS-US interval in initial training. (2) General transfer might arise from stimulus generalization from the initial CS to the new CS. However, in the present experiments and in previous demonstrations of general transfer (Kehoe \& Holt, 1984; Westbrook \& Homewood, 1982), tests for immediate transfer from the original CS to the new CS have consistently yielded negative results. Certainly, stimulus generalization is not a necessary condition for the appearance of general transfer.

Although adaptation and stimulus generalization may be discounted, two candidates remain:

Background neutralization. General transfer may arise indirectly from the neutralization of background stimuli that would otherwise compete with the discrete CS for the animal's processing resources (Mackintosh, 1977; Seraganian, 1979; Westbrook \& Homewood, 1982). The results of Experiment 2 are not encouraging for a background neutralization hypothesis, since the increase in CS-US interval in Stage 2 might be expected to have produced some increase in the salience or associative strength of background stimuli.

Superordinate learning. General transfer may result from some superordinate learning process, regardless of whether or not that process becomes independent of the original association. For example, Thomas (1970) has explained general transfer between discrimination learning problems by contending that the animal acquires not only a specific discrimination during initial training but also a "general attentiveness" to stimulus differences. Thomas's hypothesis is a special case of a more general hypothesis that, during initial training, the animal acquires not only specific associations but also a sensitivity to the structural relations between the stimulus, response, and reinforcers (cf. Levine, 1959; Restle, 1975, p. 168; Rodgers \& Thomas, 1982). This sort of hypothesis claims that the magnitude of general transfer between two tasks will depend on their similarity in terms of the structural relations between events. For example, in the present experiments, the consistent, contiguous relation between the CS and US may be the key structural element common to both tasks. The experimental strategy dictated by this approach would aim at determining whether positive transfer would occur between tasks with identical relational structures and, similarly, whether no transfer or negative transfer would occur between tasks with different relational structures. Part of such a strategy would aim at determining what relations the subject regards as crucial to making up "identical structures." For example, initial CS-US pairings might enhance the rate of differentiation between a $\mathrm{CS}+$ and a CS - in a subsequent discrimination learning task, depending on whether the initial CS-US pairings effectively constitute discrimination training between the reinforced CS and the unreinforced stimuli of the ITI.

\section{REFERENCES}

BunCH, M. E. (1936). The amount of transfer in rational learning as a function of time. Journal of Comparative Psychology, 22, 325-337.

Bunch, M. E. (1939). Transfer of training in the mastery of an antagonistic habit after varying intervals of time. Journal of Comparative Psychology, 28, 189-200.

Bunch, M. E. (1944). Cumulative transfer of training under different temporal conditions. Journal of Comparative Psychology, 37, 265-272.

Bunch, M. E., \& McCraven, V. (1938). Temporal course of transfer in the learning of memory material. Journal of Comparative Psychology, 25, 481-496.

Ellis, H. C. (1965). The transfer of learning. New York: Macmillan.

Estes, W. K. (1955). Statistical theory of spontaneous recovery and regression. Psychological Review, 62, 145-154.

Frey, P. W., \& Butler, C. S. (1977). Extinction after aversive conditioning: An associative or nonassociative effect. Learning and Motivation, 8, 1-17.

FreY, P. W., \& Ross, L. E. (1968). Classical conditioning of the rabbit eyelid response as a function of interstimulus interval. Journal of Comparative and Physiological Psychology, 65, 246-250.

Frey, P. W., \& SEars, R. J. (1978). Model of conditioning incorporating the Rescorla-Wagner associative axiom, a dynamic attention process, and a catastrophe rule. Psychological Review, 85, 321-340.

Friedes, D. (1974). Human information processing and sensory modality: Cross-modal functions, information complexity, memory, and deficit. Psychological Bulletin, 81, 284-310.

Gormezano, I. (1966). Classical conditioning. In J. B. Sidowski (Ed.), Experimental methods and instrumentation in psychology. New York: McGraw-Hill.

HaRLow, H. (1959). Learning set and error factor theory. In S. Koch (Ed.), Psychology: A study of a science (Vol. 2). New York: McGraw-Hill.

Hinson, R. E. (1982). Effects of UCS preexposure on excitatory and inhibitory rabbit eyelid conditioning: An associative effect of conditioned contextual stimuli. Journal of Experimental Psychology: Animal Behavior Processes, 8, 49-61.

Hoehler, F. K., Kirschenbaum, D. S., \& Leonard, D. W. (1973). The effects of overtraining and successive extinctions upon nictitating membrane conditioning in the rabbit. Learning and Motivation, 4, 91-101.

Hull, C. L. (1943). Principles of behavior. New York: AppletonCentury-Crofts. 
Kehoe, E. J., Feyer, A., \& Moses, J. L. (1981). Second-order conditioning of the rabbit's nictitating membrane response as a function of the CS2-CS1 and CS1-US intervals. Animal Learning \& Behavior, 9, 304-315.

Kehoe, E. J., Gibbs, C. M., Garcia, E., \& Gormezano, I. (1979). Associative transfer and stimulus selection in classical conditioning of the rabbit's nictitating membrane response to serial compound CSs. Journal of Experimental Psychology: Animal Behavior Processes, 5, 1-18.

Kehoe, E. J., \& Holt, P. E. (1984). Transfer across CS-US intervals and sensory modalities in classical conditioning of the rabbit. Animal Learning \& Behavior, 12, 122-128.

LeONARD, D. W. (1975). Partial reinforcement effects in classical aversive conditioning in rabbits and human beings. Journal of Comparative and Physiological Psychology, 88, 596-608.

LEvine, M. (1959). A model of hypothesis behavior in discrimination learning set. Psychological Review, 66, 353-366.

Mackintosh, N. J. (1975). A theory of attention: Variation in the associability of stimuli with reinforcement. Psychological Review, 82, 276-298.

Mackintosh, N. J. (1977). Stimulus control: Attentional factors. In W. K. Honig \& J. E. R. Staddon (Eds.), Handbook of operant behavior. Englewood Cliffs, NJ: Prentice-Hall.

Meck, W. H., \& Church, R. M. (1982). Abstraction of temporal attributes. Journal of Experimental Psychology: Animal Behavior Processes, 8, 226-243.

Mis, F. W., \& Moore, J. W. (1973). Effect of preacquisition UCS exposure on classical conditioning of the rabbit's nictitating membrane response. Learning and Motivation, 4, 108-114.

PAvlov, I. P. (1927). Conditioned reflexes (G. V. Anrep, Trans.). London: Oxford University Press.

Postman, L., \& Schwartz, M. (1964). Studies of learning to learn. I. Transfer as a function of method of practice and class of verbal materials. Journal of Verbal Learning and Verbal Behavior, 3, 37-49.

Prokasy, W. F., \& Papsdorf, J. D. (1965). Effects of increasing the interstimulus interval during classical conditioning of the albino rabbit. Journal of Comparative and Physiological Psychology, 60, 249-252.

REBERG, D. (1972). Compound tests for excitation in early acquisition and after prolonged extinction of conditioned suppression. Learning and Motivation, 3, 246-258.

Rescorla, R. A., \& Heth, C. D. (1975). Reinstatement of fear to an extinguished conditioned stimulus. Journal of Experimental Psychology: Animal Behavior Processes, 1, 88-96.

Rescorla, R. A., \& Wagner, A. R. (1972). A theory of Pavlovian conditioning: Variations in the effectiveness of reinforcement and nonreinforcement. In A. Black \& W. F. Prokasy (Eds.), Classical conditioning II. New York: Appleton-Century-Crofts.

Restle, F. (1975). Learning: Animal behavior and human cognition. New York: McGraw-Hill.

Richards, R. W., \& Sargent, D. M. (1983). The order of presentation of conditioned stimuli during extinction. Animal Learning \& Behavior, 11, 229-236.

Rodgers, J. P., \& Thomas, D. R. (1982). Task specificity in nonspecific transfer and in extradimensional stimulus generalization in pigeons. Journal of Experimental Psychology: Animal Behavior Processes, 8, 301-312.

Scandrett, J., \& Gormezano, I. (1980). Microprocessor control and A-D data acquisition in classical conditioning. Behavior Research Methods \& Instrumentation, 12, 120-125.

Seraganian, P. (1979). Extradimensional transfer in the easyto-hard effect. Learning and Motivation, 10, $39-57$.

Seraganian, P., \& Popova, Y. I. (1976). Cross-modal transfer of a conditioned flexion response in dogs. Pavlovian Journal of Biological Sciences, 11, 162-174.

Smith, M., Coleman, S. R., \& Gormezano, I. (1969). Classical conditioning of the rabbit's nictitating membrane response at backward, simultaneous and forward CS-US intervals. Journal of Comparative and Physiological Psychology, 69, 226-231.

Smith, M., \& Gormezano, I. (1965). Effects of alternating classical conditioning and extinction sessions on conditioned nictitating membrane response of the rabbit. Psychonomic Science, 3, 91-92.

Surton, R. S., \& BARto, A. G. (1981). Toward a modern theory of adaptive networks: Expectation and prediction. Psychological Review, 88, 135-170.

Thомаs, D. R. (1970). Stimulus selection, attention, and related matters. In J. H. Reynierse (Ed.), Current issues in animal learning. Lincoln: University of Nebraska Press.

Thomas, D. R., Mille R, J. T., \& Svinicki, J. G. (1971). Nonspecific transfer effects of discrimination training in the rat. Journal of Comparative and Physiological Psychology, 74, 96-101.

Westbrook, R. F., \& Homewood, J. (1982). The effects of a flavour toxicosis pairing upon long-delay, flavour aversion learning. Quarterly Journal of Experimental Psychology, 34B, 139-149.

(Manuscript received October 28, 1983; revision accepted for publication February 3, 1984.) 